\title{
A RELAÇÃO ENTRE COMPETÊNCIA EPISTÊMICA E CONHECIMENTO NA TEORIA DE ERNEST SOSA
}

\author{
Kátia M. Etcheverry ${ }^{1}$
}

Resumo: Este artigo enfoca a relação de atribuição entre competência e crença verdadeira presente em explicaçóes de conhecimento em termos de virtudes epistêmicas como a de Ernest Sosa. A ideia central é que, em casos de conhecimento, o fato de o agente formar uma crença verdadeira é atribuível à sua competência cognitiva (condição da competência), e não a algum fator de sorte. Os críticos apresentaram casos nos quais, alegadamente, ou o agente tem conhecimento sem satisfazer a condição da competência (portanto, a condição da competência não seria necessária para conhecimento); ou, apesar da satisfaçáo da condição da competência, o agente não tem conhecimento (portanto, a condiçáo da competência náo seria suficiente para o conhecimento). $\mathrm{O}$ cerne da questâo reside em como conceber adequadamente a condição da competência para o conhecimento, e a relação subjacente entre competência e sucesso no domínio epistêmico. Este artigo explora a concepção de Sosa dessa relação, em termos de "sucesso cognitivo que manifesta a competência do agente", e argumenta que essa posiçáo pode dar uma resposta mais direta aos críticos do que outras explicaçóes de conhecimento em termos de virtudes epistêmicas.

Palavras-chave: Condição da Competência. Confiabilismo da Virtude. Ernest Sosa. Conhecimento. Manifestação da Competência. Relação de Atribuição.

\section{INTRODUÇÃo}

Ernest Sosa é um dos principais defensores do confiabilismo da virtude $^{2}$ e de explicaçóes de conhecimento como um tipo de desempenho bem-sucedido atribuível ao caráter cognitivo confiável do conhecedor. Conforme Sosa (2011, p. 86), "A Epistemologia da Virtude pode ser

\footnotetext{
${ }^{1}$ Pontifícia Universidade Católica do Rio Grande do Sul (PUC/RS), Porto Alegre, RS - Brasil. (D) https://orcid.org/0000-0002-0093-1089 E-mail: kaetch@gmail.com

${ }^{2}$ A epistemologia da virtude tem duas linhagens: (i) confiabilismo da virtude (Sosa, Greco, Pritchard, Turri); e (ii) responsibilismo de virtude (Montmarquet, Zagzebski, Baehr). Este artigo enfoca apenas teorias confiabilistas da virtude.
}

https://doi.org/10.1590/0101-3173.2021.v44dossier2.13.p185

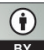

This is an open-access article distributed under the terms of the Creative Commons Attribution License. 
formulada como a visão de que conhecimento é crença cujo sucesso é 'creditável' ao conhecedor". A intuição norteadora nessa posição é que, em casos de conhecimento, ter formado uma crença que é verdadeira deve estar adequadamente relacionado ao caráter cognitivo do agente, de modo que conhecimento é definido como crença verdadeira creditável às competências cognitivas do agente (CVCA). Nesta perspectiva, uma crença justificada e verdadeira que não satisfaça a condição da competência, qual seja, a de ser atribuível ao caráter cognitivo do agente, não pode ser um caso de conhecimento. Esta explicação de conhecimento pretende ser imune a contraexemplos de tipo Gettier, ${ }^{3}$ uma vez que a condição da competência para o conhecimento não é satisfeita nos casos em que há algum fator de sorte (real ou contrafactual) envolvido na produção da crença justificada e verdadeira. Como coloca Sosa (2015, p. 72), “[...] uma realização [cognitiva] é creditável [ao agente] na medida em que ela resulta da competência [do agente] e não de sorte." Outra vantagem dessa posiçáo seria a de que a condição da competência permite explicar por que conhecimento é mais valioso do que mera crença verdadeira: conhecimento é crença verdadeira devida ao caráter epistêmico virtuoso do agente.

Propostas de CVCA foram atacadas pela crítica por meio de dois tipos de contraexemplos: (i) casos nos quais o agente teria conhecimento sem satisfazer a condição da competência (portanto, a condição da competência não seria necessária para o conhecimento); e casos nos quais, apesar de ter satisfeito a condição da competência o agente não teria conhecimento (portanto, a condição da competência não seria suficiente para o conhecimento). A conclusão pretendida pelos opositores é que a condição da competência seria ou muito forte (excluindo casos legítimos de conhecimento); ou muito fraca (tomando casos de ignorância como sendo casos de conhecimento), de modo que a condição da competência falharia em distinguir entre casos de conhecimento e casos de ignorância. $\mathrm{O}$ cerne da questáo reside em como conceber, de modo adequado, a condiçáo da competência para o conhecimento e em especial a relação subjacente entre competência e sucesso no domínio epistêmico. A concepção de Sosa dessa relação (SOSA, 2007; 2009; 2010; 2011; 2015), em termos de manifestação da competência epistêmica do agente no sucesso cognitivo, é examinada neste artigo a fim de motivar a proposta de que ela

\footnotetext{
3 Colocado de modo sucinto, Edmund Gettier (1963) propôs dois contraexemplos à suficiência da análise tripartite de conhecimento como crença verdadeira justificada. Esses contraexemplos se multiplicaram dentro da extensa discussão que o artigo de Gettier provocou na epistemologia contemporânea, com ênfase na ideia de que conhecimento não pode ser obtido de modo acidental.
} 
coloca a teoria de Sosa em posição de responder aos críticos de modo mais efetivo do que outras teorias da virtude epistêmica (GRECO, 2003; 2010; 2012; PRITCHARD, 2009; 2012).

\section{CONHECIMENTO COMO CRENÇA VERDADEIRA CREDITÁVEL AO AGENTE EPISTÊMICO (CVCA)}

Um ponto central nas explicaçôes de conhecimento em termos de competências (habilidades, virtudes) ${ }^{4}$ é que, nos casos de conhecimento, as competências cognitivas do agente devem estar apropriadamente envolvidas não apenas na produção da crença, mas também no sucesso em alcançar a verdade, de modo que ter formado uma crença que é verdadeira se deve à competência do agente epistêmico, e não a outra coisa qualquer. Além disso, para que as habilidades cognitivas do agente estejam "apropriadamente envolvidas" no sucesso cognitivo o agente deve estar, interna e externamente, em condiçôes adequadas para o exercício dessas habilidades. Assim entendida, a relação de atribuição entre sucesso cognitivo e a competência cognitiva do agente, noção central em explicaçóes de conhecimento em termos de virtude epistêmica, foi concebida de duas maneiras: (i) a atribuição de sucesso cognitivo é determinada pela saliência explicativa das competências cognitivas do agente na explicação de por que o agente obteve sua crença verdadeira (GRECO, 2003; 2009; 2010; 2012; PRITCHARD, 2012); e (ii) a atribuição de sucesso cognitivo depende de que as competências cognitivas do agente se manifestem na aquisição da crença verdadeira em questão (BRONCANO-BERROCAL, 2017; KELP, 2013; SOSA, 2010; 2011; 2015; TURRI, 2011; 2016).

\subsection{CondiçÁo da COMPETÊNCIA EM TERMOS DE MANIFESTAÇÃo DA COMPETÊNCIA EPISTÊMICA}

De acordo com Sosa $(2007 ; 2011 ; 2015)$, conhecimento é "crença apta”, um desempenho cognitivo bem-sucedido no qual o agente crê em uma verdade por meio do exercício apropriado de suas competências cognitivas. Desse modo, ter formado uma crença verdadeira é creditável ao agente epistêmico e não à sorte. Crenças aptas obedecem à estrutura normativa AAA

\footnotetext{
${ }^{4}$ Esses termos são equivalentes. "As virtudes ou competências epistêmicas são habilidades. [...] um tipo especial de disposiçóes [...] associadas a um conjunto de condicionais que têm como antecedentes gatilhos [desencadeadores] e como consequentes manifestaçōes [resultantes]”. (SOSA. 2011, p. 80)
} 
porque são: acuradas (verdadeiras), hábeis (competentes) e aptas (verdadeiras porque hábeis)..$^{5}$

Segundo Sosa (2015, p. 26-30), a relação de atribuição, presente na condição da competência, é interpretada em termos de manifestação, de maneira que uma crença é apta só se sua acurácia manifesta a competência cognitiva do agente. Competências cognitivas são disposições estáveis do agente para ter sucesso em seus desempenhos, desde que ele esteja em determinadas condiçóes, internas e externas, relevantes. Na terminologia de Sosa, um agente possui competência "plena" ou "completa" quando essa competência satisfaz a estrutura SSS: ${ }^{6}$ Habilidade assentada (habilidade estavelmente integrada ao caráter cognitivo do agente), Forma (condiçôes internas do agente, tais como estar acordado ou dormindo, saudável ou doente), e Situação (condiçóes externas do agente, tais como estar em condições de boa ou má iluminação, ou em um ambiente epistemicamente amigável ou hostil). Desse modo,

[...] uma disposição pode se manifestar em determinado resultado somente se ela explicar apropriadamente esse resultado. Isso requer a conjunção de habilidade assentada, forma e situação, de modo a causar a manifestação sob a ação do gatilho [evento desencadeador]. (SOSA, 2015, p. 30).

Em outras palavras, diante de um evento desencadeador, competências que satisfazem a estrutura SSS necessariamente se manifestam no resultado bem-sucedido (conhecimento). Por fim, se o sucesso cognitivo manifesta uma competência epistêmica do agente, então esse sucesso é satisfatoriamente explicado por essa manifestação de competência, pois não pode haver manifestação de competência em um sucesso específico sem que essa manifestação seja relevante para a ocorrência desse sucesso.

Por conseguinte, "a manifestação [da competência epistêmica] determina crédito e descrédito [no domínio epistêmico]” (SOSA, 2015, p. 29), e dizer que uma crença verdadeira manifesta a competência do agente equivale dizer que ter alcançado crença verdadeira não foi acidental mas sim creditável à competência desse agente, sendo portanto um caso de conhecimento. Nesse sentido, crédito epistêmico

\footnotetext{
5 Em inglês: accurate, adroit, apt.

${ }^{6}$ SSS se refere aos termos em inglês Skill (habilidade), Shape (forma) e Situation (situação).
} 
[...] parece antes uma noção causal, onde a responsabilidade causal por determinado resultado é atribuída à entidade "creditada" (pelo menos parcialmente) por esse resultado. [...]. É esse tipo de crédito que eu teria em mente ao dizer que uma competência do agente que crê e, portanto, o próprio agente, deve ser creditável pela verdade de uma dada crença que é um caso de conhecimento. [...] S saber que p ao crer dessa forma é uma questão de a correção de sua crença manifestar uma competência assentada nele. A existência da crença pode decorrer de um exercício dessa competência, mas isso não é suficiente. É antes a sua correção que deve manifestar a competência. (SOSA, 2011, p. 86-87).

Nessa passagem, Sosa deixa clara uma distinção importante entre exercício da competência, que resulta na existência da crença, e manifestação da competência, que resulta no sucesso cognitivo (crença verdadeira) devido à competência do agente. ${ }^{7}$ A partir disso, parece ficar claro que, em Sosa, exercícios de competência podem não ser bem-sucedidos, i.e., o mero exercício de uma competência pode não levar a conhecimento. Contudo, exercícios de competência resultam em crenças com algum status epistêmico positivo: essas crenças são hábeis ou competentes. Por outro lado, a manifestação da competência é sempre um caso de sucesso cognitivo, dado que manifestação é uma relação de dois relata, a saber, competência e sucesso, que só ocorre se esses relata estão presentes: "[a manifestação é] uma relação primitiva [...] que tem manifestaçôes de resultados (desempenhos bem-sucedidos) de um lado, e competências (perceptuais, agenciais, epistêmicas) de outro." (SOSA, 2015, p. 31) Assim, dizer que uma crença verdadeira manifesta a competência do agente é dizer que esse sucesso é devido a ele, e, portanto, alcançar crença verdadeira não foi acidental.

\subsection{Condiçáo da CompetênCIa EM termos de saliênCia eXPlicativa da COMPETÊNCIA EPISTÊMICA}

Conforme Greco $(2009 ;$ 2012) em casos de conhecimento, o fato de o agente formar sua crença por meio de sua competência cognitiva é o fator explicativo mais saliente na explicação da obtenção de crença verdadeira.

\footnotetext{
7 Lisa Miracchi (2015) sugere uma distinção semelhante, mas com um detalhamento e propósitos diversos. Sua intenção é especificar um tipo de habilidade que serve às necessidades de uma epistemologia da virtude do conhecimento primeiro: "a epistemologia da virtude direta sustenta que competências para saber admitem dois tipos de exercícios: manifestações, que são constitutivamente realizaçóes (casos de conhecimento) e exercícios degenerados, que são constitutivamente fracassos (casos de crença falsa justificada e de crença gettierizada)." (p. 355)
} 
A saliência explicativa da competência cognitiva deriva dos interesses e propósitos envolvidos, e depende da ausência de eventuais aspectos "estranhos ou incomuns" (GRECO, 2012, p. 9), apenas quando o mundo está em seu modo normal, ou seja, conducente à verdade, as habilidades cognitivas do agente têm saliência padrão. Nessas situaçóes a competência do agente explica seu sucesso cognitivo de modo que ter sido cognitivamente bem-sucedido é creditável a seu caráter cognitivo virtuoso. Diferentemente, em situaçôes de tipo Gettier onde tipicamente ocorrem fatores "estranhos ou incomuns", a saliência explicativa não estaria nas habilidades cognitivas do agente mas em algum outro fator, de modo que a obtenção de crença verdadeira seria meramente acidental.

Nos casos de conhecimento, habilidade e mundo conspiram para produzir crença verdadeira no modo usual, [de modo que] a habilidade retém sua saliência padrão, e entáo julgamos que $S$ sabe. Nos casos tipo Gettier, a habilidade e o mundo conspiram para produzir uma crença verdadeira, mas não no modo usual. Em vez disso, algo estranho ou incomum acontece [...] Consequentemente, a relevância é retirada das habilidades de S, e então julgamos que S não sabe. (GRECO, 2012, p. 9).

Duncan Pritchard concebe a relação de atribuição de forma semelhante a de Greco, mas mais fraca: um sucesso cognitivo é atribuível às habilidades cognitivas do agente quando o exercício dessas habilidades é uma parte importante, ainda que não a mais importante, de por que o agente formou (ou sustenta) essa crença. Nessa linha de pensamento, seria dispensável estabelecer o grau de relevância explicativa . Além disso, Pritchard defende uma epistemologia da virtude antissorte que associa uma condição de competência (ou habilidade, como ele diz) e uma condição antissorte (segurança). Como resultado, a condição da competência pode ser enfraquecida, dado que seu encargo teórico é compartilhado com a condição antissorte, e requerer apenas que o sucesso cognitivo seja creditado à capacidade do agente "em grau significativo".

Essa proposta (a epistemologia da virtude antissorte) incorpora tanto uma condição antissorte (a exigência de que a crença verdadeira seja segura) quanto uma condição de habilidade. Observe que a condição de habilidade em jogo aqui é aquela proposta por uma epistemologia da virtude fraca ao invés de uma epistemologia da virtude forte, exceto que, em conformidade com a natureza híbrida da explicação, estamos interpretando esta condiçáo [da habilidade] como exigindo que o sucesso cognitivo seguro do agente seja em grau significativo devido à sua agência cognitiva. (PRITCHARD, 2012, p. 273). 


\section{CVCA: OBJEÇÓES}

Os críticos ofereceram dois contraexemplos que pretendem mostrar que a condição de competência não é nem necessária nem suficiente para conhecimento. Em primeiro lugar, Lackey $(2007 ; 2009)$ coloca que existem casos de conhecimento testemunhal em que a condição de competência (ou a condição do crédito em sua terminologia) não é satisfeita porque as habilidades cognitivas do ouvinte não são a parte mais saliente da cadeia causal que explica porque ele formou uma crença verdadeira. Sendo assim, pode haver conhecimento sem competência (ou crédito epistêmico). Por outro lado, Pritchard $(2010 ; 2012)$ alega que a condição de competência (ou habilidade em sua terminologia) não é uma condição suficiente para o conhecimento, uma vez que em situaçôes epistemicamente inseguras, como no famoso caso dos celeiros falsos, ${ }^{8} \mathrm{o}$ agente forma uma crença verdadeira por meio de suas habilidades cognitivas, mas ele não tem conhecimento porque sua crença competente e verdadeira não é segura, pois ele formou uma crença que é verdadeira apenas por sorte. Portanto, se pode haver crença competente e verdadeira que não é um caso de conhecimento, então a condição da competência não é suficiente para discriminar conhecimento e ignorância em certos casos. Essa conclusão motiva a epistemologia da virtude antissorte de Pritchard, segundo a qual conhecimento requer tanto uma condição antissorte quanto uma condição de competência (habilidade).

\subsection{CONHECIMENTO SEM COMPETÊNCIA}

Jennifer Lackey apresentou o seguinte contraexemplo contra CVCA:

Morris, tendo acabado de chegar à Chicago [pela primeira vez], deixa a estaçâo ferroviária e procura obter informaçóes sobre como chegar à Sears Tower. Ele olha em volta, se aproxima do primeiro adulto que passa por perto e pergunta como chegar ao destino desejado. O passante, que por acaso é um residente de Chicago que conhece a cidade extraordinariamente bem, fornece a Morris direções impecáveis sobre como chegar à Sears Tower, dizendo-lhe que ela está localizada a dois quarteiróes a leste da estaçáo ferroviária. Sem hesitar, Morris forma a crença verdadeira correspondente. (LACKEY, 2007, p. 352).

\footnotetext{
${ }^{8}$ Esse caso foi apresentado por Goldman (1976) que posteriormente (1992) refere que lhe foi sugerido por Carl Ginet.
} 
De acordo com Lackey, o caso de Morris mostra que há casos de conhecimento obtido via testemunho onde o sucesso cognitivo não parece ser explicado pelas habilidades cognitivas do ouvinte, mas sim pelas do informante. Em outras palavras, nestes casos, temos sucesso cognitivo, i.e., conhecimento, que não se deve principalmente à competência do ouvinte. Desse modo, prossegue a objeçáo, se podemos ter conhecimento sem que a condição da competência seja satisfeita, então essa condição não é necessária para o conhecimento.

\subsection{COMPETÊNCIA SEM CONHECIMENTO}

A segunda linha de objeção ataca a suficiência da condição de competência para explicar conhecimento, mostrando casos onde essa condição não consegue explicar a falta de conhecimento do agente. $\mathrm{O}$ caso dos celeiros falsos é um dos mais citados na literatura, nele Barney caminha em um ambiente epistêmico hostil, onde há vários celeiros falsos, meras fachadas imitando celeiros reais, e um único celeiro genuíno, diante do quel ele forma a crença de que "isso é um celeiro". " Sua crença é verdadeira e resulta do sucesso de suas habilidades cognitivas em conectá-lo ao fato de que está diante de um celeiro de verdade, mas intuitivamente Barney não tem conhecimento. Este caso constitui um desafio importante para CVCA pois, embora a competência cognitiva de Barney explique por que ele formou uma crença verdadeira, ele não sabe que está diante de um celeiro, pois ele poderia muito facilmente ter formado uma crença falsa no território dos celeiros falsos. A fim de explicar a ignorância de Barney, a teoria deve poder acomodar a ocorrência de um fator de sorte que está envolvido na obtenção da crença verdadeira e faz com que a crença de Barney seja insegura. De acordo com Pritchard, Barney está sob o efeito de sorte ambiental, de modo que mesmo uma sua crença seja bem formada ela sempre será verdadeira de modo acidental. ${ }^{10}$ Em outras palavras,

${ }^{9}$ Essa apresentação do caso é uma versão do caso original apresentado por Goldman.

${ }^{10}$ Resumindo, na terminologia de Pritchard, a ignorância em todos os casos do tipo Gettier é explicada pela presença de algum fator de "sorte verítica", que pode ser de dois tipos: sorte interferente e sorte ambiental. Nos casos tipo Gettier onde ocorre sorte interferente, embora haja algo de errado na forma como a crença do agente é formada (como no exemplo proposto por Chisholm (1977) no qual o objeto que o agente está olhando não é uma ovelha, mas se parece com uma ovelha), ocorre um fator de sorte que torna a crença verdadeira (de fato há uma ovelha escondida atrás do objeto que se parece com uma ovelha), de modo que podemos dizer que a sorte interfere entre a crença e o fato. Já nos casos tipo Gettier onde ocorre sorte ambiental (como o caso dos celeiros falsos) não há nada de errado com a forma como o agente forma sua crença, mas o ambiente é tal que mesmo uma crença bem formada será verdadeira apenas por sorte. Ver Pritchard (2009, capítulos 3 e 4) 
há casos em que a condição de competência (ou habilidade, como denomina Pritchard) não consegue estabelecer quando temos e quando não temos conhecimento. Sendo assim, Pritchard afirma que a teoria de Sosa ${ }^{11}$ falha em explicar a ignorância devido à sorte ambiental. ${ }^{12}$

Tomados em conjunto, os dois contraexemplos apresentados acima representam um desafio formidável para explicaçóes de conhecimento que requerem a condição da competência: enquanto o caso dos celeiros falsos exige que a condição da competência seja forte o suficiente para negar conhecimento a Barney, o caso proposto por Lackey exige que a condição da competência seja fraca o suficiente para acomodar casos de conhecimento testemunhal.

\section{CVCA: RESPOSTAS AOS CRÍTICOS}

\subsection{EM TERMOS DE MANIFESTAÇÁO DA COMPETÊNCIA EPISTÊMICA DO AGENTE}

Segundo Sosa, uma crença verdadeira é creditável à competência do agente mesmo quando o sucesso cognitivo não é atribuído exclusivamente à sua competência epistêmica individual.

$S$ sabe que p se, e somente se, a correçáo da crença de $S$ de que p manifesta, parcial ou totalmente, uma competência epistêmica de $S$ para formar ou sustentar crenças, e ao fazê-lo também manifesta de modo pleno uma (possivelmente mais complexa) competência assentada pelo menos parcialmente em S. (SOSA, 2011, p. 88).

Assim, em casos de conhecimento testemunhal, a crença verdadeira resulta da manifestação de uma competência cognitiva que está parcialmente assentada naquele que recebe o testemunho. Nestes casos, o sucesso cognitivo também se deve à manifestação da competência cognitiva de um grupo constituído pelas várias competências cognitivas, tanto de falantes como de ouvintes que integram a cadeia testemunhal.

\footnotetext{
${ }^{11}$ Pritchard não ataca especificamente a teoria de Sosa, mas toda explicação "robusta" de CVCA que requeira apenas a satisfação da condição da habilidade (ou competência) para que uma crença verdadeira seja um caso de conhecimento.

${ }^{12}$ Este ponto é o divisor que separa explicaçôes de conhecimento que requerem apenas a condição da competência, como Sosa e Greco, de explicaçóes, como a de Pritchard, que considera que conhecimento requer duas condições independentes: a condiçấo antissorte e a condição de competência (habilidade).
} 
Suponha que a correção do juízo [crença] de uma pessoa manifeste parcialmente sua competência, a qual é parcialmente constitutiva da competência completa assentada no grupo. Nesse caso, a correção de seu juízo pode manifestar parcialmente sua competência [individual] constitutiva, ao mesmo tempo que manifesta mais plenamente a competência completa assentada no grupo, sendo que a pessoa fazer parte deste grupo é essencial para que esse desempenho seja apto. (SOSA, 2015, p. 117).

No que diz respeito ao caso dos celeiros falsos, a resposta de Sosa leva em consideração sua distinção entre conhecimento animal e conhecimento reflexivo - "crença apta" e "crença aptamente notada", respectivamente e o nível excelente de "conhecimento pleno", no qual "o conhecimento reflexivo auxilia a guiar a crença de primeira ordem de modo a que seja apta”. (SOSA, 2011, p. 13). Tendo em vista esses níveis hierárquicos de conhecimento, no caso dos celeiros falsos, dadas as peculiaridades do ambiente epistêmico em que se encontra, Barney, apesar de ter conhecimento animal, dificilmente poderia ter conhecimento reflexivo, e certamente nunca teria conhecimento pleno. A crença de primeira ordem de Barney é apta, i.e., ela é acurada, hábil e acurada porque hábil, talvez Barney pudesse ter uma crença apta aptamente notada manifestando uma competência reflexiva (e altamente sofisticada); mas Barney nunca poderia ter conhecimento pleno porque "para ter conhecimento pleno, Barney deve saber que não erraria facilmente se, em suas condiçóes, ele afirmasse que está diante de um celeiro”. (SOSA, 2015, p. 79). Mas Barney não está em posição de satisfazer essa condição contrafactual de segurança, pois, devido à massiva presença de falsos celeiros na região, não há condições ambientais apropriadas para a manifestação de sua competência. $\mathrm{Na}$ terminologia de Sosa, apenas competências completas, que satisfazem a estrutura normativa SSS que inclui a condição de segurança, podem se manifestar. Assim, a crença de Barney é segura apenas se ele "possuir uma competência completa em virtude da qual, de maneira confiável o suficiente, ele afirmaria correta e aptamente sobre essa questão, se ele afirmasse por meio do exercício dessa competência”. (SOSA, 2015, p. 80). 


\subsection{EM TERMOS DE SALIÊNCIA EXPLICATIVA DA COMPETÊNCIA EPISTÊMICA DO AGENTE}

Greco $(2010 ; 2012)$ revisa sua posição anterior (2003), exposta na seção 1.2 , tendo em vista algumas críticas, assumindo que a relação de atribuição deve ter natureza pragmática, relacionada ao modo como as habilidades do agente estáo envolvidas no sucesso cognitivo, que será "apropriado" caso "sirva regularmente a propósitos relevantes”. (GRECO, 2012, p. 14). Além disso, a saliência explicativa da competência do agente na explicação de conhecimento deve ser considerada em termos qualitativos e não quantitativos. Assim,

[o] novo quadro mantém a ideia de que as habilidades de $S$ são importantes na história causal sobre como $S$ chega a ter uma crença verdadeira, mas nele a "importância" é qualitativa em vez de quantitativa. Em vez de dizer que as habilidades de $S$ devem ser "importantes o suficiente" na história causal, dizemos que elas devem ser "importantes da maneira certa”. (GRECO, 2012, p. 12).

Conforme referido anteriormente, na concepção de Greco, a competência epistêmica do agente teria "saliência padrão" na explicação da obtenção de crença verdadeira, salvo em certas situaçóes, como as do tipo Gettier, onde essa competência epistêmica não se relaciona com o mundo em seu modo usual, quando "algo estranho ou incomum acontece [...] a relevância é retirada das habilidades de $S$, e então julgamos que $S$ náo sabe.” (GRECO, 2012, p. 9) No caso dos celeiros falsos é precisamente isso que ocorre, o ambiente epistêmico não se apresenta em seu modo "normal", ou seja, de um modo que seja favorável à aquisição de crenças verdadeiras, e por isso, Barney não seria competente nesse ambiente para identificar um celeiro genuíno.

Em primeiro lugar, notamos que habilidades em geral são sempre relativas a ambientes. [...] Em geral, quando atribuímos uma habilidade [a um agente], temos em mente algum ambiente relevante, bem como condiçóes relevantes, etc. Em segundo lugar, podemos agora afirmar que Henry [isto é, Barney] não tem a habilidade de discriminar entre [objetos que são] celeiros e [objetos que] não [são] celeiros, relativamente ao ambiente em que se encontra. (GRECO, 2010, p. 76).

Henry crê por meio de uma disposição que é confiável relativamente a ambientes normais, mas não ao ambiente em que ele se encontra. Consequentemente, Henry não sabe que o objeto que ele vê é um celeiro. (GRECO, 2012, p. 22). 
Por conseguinte, Greco entende que Barney não tem conhecimento porque a obtenção de crença verdadeira, no ambiente dos falsos celeiros, requer uma habilidade que Barney não possui, qual seja, a de discrinimar entre fachadas de celeiro e celeiros genuínos. Essa resposta parece insatisfatória pois ela conduz a pelo menos duas inquietaçóes. Primeiramente, ela não permite contemplar o que a crença de Barney tem de epistemicamente positivo. Afinal, ele exercita sua habilidade visual normalmente confiável, e forma por meio dela uma crença verdadeira, por isso parece que sua crença tem algum status epistêmico positivo. Em segundo lugar, parece problemático conceber habilidades com tamanho refinamento, especificando, como é o caso, uma habilidade de distinguir entre fachadas de celeiro e celeiros genuínos no território dos celeiros falsos.

Quanto ao caso do conhecimento testemunhal, Greco entende que Morris tem conhecimento porque exercita suas habilidades cognitivas relevantes no "modo correto", de maneira que ter formado uma crença verdadeira é creditável a essas habilidades cognitivas e não a algum fator de sorte.

Em casos de conhecimento testemunhal e conhecimento envolvendo cognição estendida, mas não nos casos tipo Gettier, o fato de $S$ crer a partir de sua habilidade contribui de modo correto para que $S$ tenha uma crença verdadeira - i.e., de uma maneira que serviria regularmente a necessidades de informação relevantes. (GRECO, 2012, p.17).

A proposta de Pritchard (2012) se afasta da visão de Greco em dois aspectos: (i) pelo enfraquecimento na condição da competência em relação à saliência explicativa apropriada para que as habilidades do agente expliquem o sucesso cognitivo, e (ii) pela inclusão de uma condição antissorte.

[...] de acordo com a natureza híbrida da explicação [de conhecimento] estamos interpretando essa condição [da habilidade] como exigindo que o sucesso cognitivo seguro do agente deva ser creditado em um grau significativo à sua agência cognitiva. Como veremos, desde que a condição da habilidade seja acompanhada por uma condição antissorte, não há necessidade de se optar por uma versão mais forte da condição da habilidade para lidar com casos que relacionados à intuição antissorte. (PRITCHARD, 2012, p. 273). 
A condição antissorte (ou condição de segurança) na proposta de Pritchard é responsável por explicar a falta de conhecimento em casos como o de Barney - sua crença não é segura. Já a condição da competência é enfraquecida, exigindo apenas que a contribuição das habilidades do agente para o sucesso cognitivo seja em "grau significativo" e não o fator mais importante, acomodando assim casos de conhecimento testemunhal como o de Morris.

\section{CONSIDERAÇÓES FINAIS}

A explicação de conhecimento como 'crença verdadeira creditável à competência epistêmica do agente' é elegante e ao mesmo tempo poderosa em ferramental teórico. Sua diversidade interna, ilustrada pelas variantes entre as propostas dos autores apresentados nesse artigo, longe de fragmentar e enfraquecer a vertente confiabilista da epistemologia da virtude, contribui para sua força e versatilidade teórica. A guisa de conclusão, gostaria de ressaltar alguns aspectos da teoria de Sosa que, a meu juízo, o colocam em posição mais fiel à elegância e força da ideia original de explicar conhecimento colocando a noçáo de virtudes epistêmicas no centro do interesse epistemológico. Sugestão essa, aliás, proposta originalmente pelo próprio Sosa (1980) há quatro décadas atrás.

Primeiramente, a concepção de Sosa é 'pura', i.e, é formulada inteiramente em termos de virtude epistêmica, em contraste com a proposta de Greco, que introduz um elemento de avaliação pragmática em sua concepção da relação de atribuição entre competência e sucesso, e também em contraste com a proposta de Pritchard, que entende que conhecimento requer a inclusáo de uma condição independente da condição da competência, a condição antissorte. Além disso, mas não menos importante, temos a vantagem teórica dada à posição de Sosa ao conceber a relação de atribuição em termos de manifestação, que permite distinguir entre crença que é o resultado do exercício de competência do agente, i.e., crença adroit ou competente, e crença que manifesta a competência do agente, i.e., conhecimento. Essa distinção permite conferir às crenças formadas por agentes em situaçóes como a de Barney algum status epistêmico positivo, ainda que não o de conhecimento em sentido filosoficamente relevante. ${ }^{13}$ Assim, a teoria de Sosa responde às

\footnotetext{
${ }^{13}$ É interessante observar quanto a este ponto que, embora uma maioria expressiva de epistemólogos considere que Barney não sabe, Sosa atribui a Barney "conhecimento animal". Mas ele se junta à reação predominante frente a este caso quando afirma que (i) dificilmente Barney poderia ter conhecimento
} 


\title{
objeções sem a necessidade de multiplicar as condiçóes para o conhecimento, ou de introduzir elementos estranhos à epistemologia da virtude.
}

ETCHEVERRY, K. M. The relation between epistemic competence and knowledge in Ernest Sosa’s theory. Trans/form/ação, Marília, v. 44, p. 173-184, Edição Especial - Dossier "Ernest Sosa", 2021.

\begin{abstract}
This paper focuses on the attribution relation between competence and true belief present in epistemic virtue accounts of knowledge such as Sosa's theory. The core idea is that in cases of knowledge the fact that the agent gets a true belief is attributable to her cognitive competence (competence condition), and not to some lucky factor. Critics have presented cases where, purportedly, the agent can either have knowledge without satisfying the competence condition (therefore, the competence condition would not be necessary for knowledge), or, despite the satisfaction of the competence condition, the agent has no knowledge (therefore, the competence condition would not be sufficient for knowledge). The crux of the matter lies in how to conceive properly the competence condition for knowledge, and the underlying relationship between competence and success in the epistemic domain. This paper explores Sosa's view of this relationship in terms of "cognitive success that manifests the agent's competence", and proposes that it provides a more direct answer to the critics than do other epistemic virtue accounts of knowledge.
\end{abstract}

Keywords: Attribution Relation. Competence Condition. Ernest Sosa. Knowledge. Manifestation of Competence. Virtue Reliabilism.

\section{REFERÊNCIAS}

BAEHR, J. The Inquiring Mind: On Intellectual Virtues and Virtue Epistemology. Oxford: Oxford University Press, 2011.

BRONCANO-BERROCAL, F. A robust enough virtue epistemology. Synthese, v. 194, n. 6, p. 2147-2174, 2017.

CHISHOLM, R. Theory of Knowledge. New Jersey: Prentice Hall, 1977.

GETTIER, E. Is Justified Belief Knowledge? Analysis, v. 23, n. 6, p. 121-123, 1963.

"reflexivo", ou seja, uma crença apta aptamente notada", que manifesta sua competência reflexiva; e (ii) certamente ele nunca poderia ter conhecimento "pleno" porque "para saber de modo pleno, Barney deve saber que se, em suas condiçôes, ele afirmasse que está diante de um celeiro, ele não facilmente erraria". (2015, p. 79). Em suma, na visâo de Sosa,nega a Barney precisamente "o tipo de conhecimento que está no centro da epistemologia tradicional, dos pirrônicos até Descartes." (SOSA, 2015, p. 2-3). 
GOLDMAN, Alvin. Discrimination and Perceptual Knowledge. The Journal of Philosophy, v. 73, p. 771-91, 1976. (Republicado em GOLDMAN, A. "Liaisons:

Philosophy Meets the Cognitive and Social Sciences". Cambridge: The MIT Press, 1992. p. 85-103.)

GRECO, J. Knowledge as credit for true belief. In: DePaul, M.; Zagzebski, L. (eds.). Intellectual virtue: Perspectives from ethics and epistemology. Oxford: Oxford University Press, p. 111-134, 2003.

GRECO, J. Knowledge and success from ability. Philosophical Studies, v. 142, p. 17-26, 2009.

GRECO, J. Achieving Knowledge: A Virtue-Theoretical Account of Epistemic Normativity”. Cambridge: Cambridge University Press, 2010.

GRECO, John. A (different) virtue epistemology. Philosophy and Phenomenological Research, v. 85, n. 1, p. 1-26, 2012.

KELP, C. Knowledge: The Safe-Apt View. Australasian Journal of Philosophy, v. 91, n. 2, p. 265-27, 2013.

LACKEY, J. Why we don't deserve credit for everything we know. Synthese, v. 158, n. 3, p. 345-361, 2007.

LACKEY, J. Knowledge and Credit. Philosophical Studies, v. 142, p. 27-42, 2009.

MIRACCHI, L. Knowledge is all you need. Philosophical Issues, v. 25, p. 353-378, 2015.

MONTMARQUET, J. A. Epistemic Virtue and Doxastic Responsibility. Lanham: Rowman and Littlefield, 1993.

PRITCHARD, D. Knowledge. London: Palgrave Macmillan, 2009.

PRITCHARD, D. Anti-Luck Virtue Epistemology. In: HADDOCK, A.; MILLAR, A.; PRITCHARD, D. (Eds.) The nature and value of knowledge: three investigations. N. York: Oxford University Press, p. 48-65, 2010.

PRITCHARD, D. Anti-Luck Virtue Epistemology. In: The Journal of Philosophy, v. 109, n. 3, p. 247-279, 2012.

SOSA, E. The raft and the pyramid: coherence versus foundations in the theory of knowledge

Midwest Studies in Philosophy, v. 5, p. 3-25, 1980.

SOSA, E. A virtue epistemology: Apt belief and reflective knowledge, vol 1. Oxford: Clarendon Press, 2007.

SOSA, E. Reflective knowledge: Apt belief and reflective knowledge, vol 2. Oxford: Oxford University Press, 2009. 
SOSA, E. How Competence matters in Epistemology. In: Philosophical Perspectives (Epistemology), v.24, p. 465-475, 2010.

SOSA, E. Judgment and Agency. Oxford: Oxford University Press, 2015.

TURRI, J. Manifest Failure: The Gettier Problem Solved. Philosophers' Imprint, v. 11, n. 8, p. 1-11, 2011.

TURRI, J. A New Paradigm for Epistemology: From Reliabilism to Abilism. IB, v. 3, n. 8, p. 189-230, 2016.

ZAGZEBSKI, L. Virtues of the Mind. Cambridge: Cambridge University Press, 1996. 